\title{
Prevalence of helminth parasites in sheep (Ovis aries) in Tangail district, Bangladesh
}

\author{
A. Sangma, N. Begum, B. C. Roy and M. O. Gani ${ }^{1}$ \\ Department of Parasitology, Bangladesh Agricultural University, Mymensingh-2202, Bangladesh and ${ }^{1}$ Bangladesh \\ Livestock Research Institute, Savar, Dhaka, E-mail: bcroy.dvm51@gmail.com
}

\begin{abstract}
Prevalence of helminths of sheep in relation to age, sex, nutritional status, management system and flock size was studied at Tangail district, Bangladesh from July to December 2010 by fecal examination. A total of 190 sheep were examined of which $154(81.1 \%)$ were positive for one or more species of helminth parasites. Seven species of helminths were identified, of them three species were trematodes, namely, Fasciola gigantica (8.4\%), Paramphistomum spp. (44.2\%) and Schistosoma indicum (3.7\%); four species were nematodes, namely, Bunostomum sp (19.0\%), Trichuris spp. (2.1\%), Strongyles (62.6\%) and Strongyloides spp. (9.5\%). No cestodes were identified. Prevalence of helminths was significantly $(p<0.01)$ higher in young sheep aged $>1-2$ year $(92.7 \%)$ than adult aged $>2$ years $(83.3 \%)$ and lamb aged $\leq 1$ year $(63.6 \%)$. Higher prevalence was recorded in female than in male sheep. In relation to nutritional status and flock size, prevalence of helminths were significantly $(p<0.01)$ higher in poor health and large flock sized animals. It is suggested that helminth infection is widely prevalent in sheep in Tangail district of Bangladesh.
\end{abstract}

Keyword: Prevalence, Helminths, Sheep, Tangail District

\section{Introduction}

Parasitism is of supreme importance in many agro-ecological zones and still a serious threat to the livestock economy worldwide (Vercruysse and Claerebout, 2001). Sheep are known to suffer from various endoparasites of which helminth infection are of great importance. Helminth infections remain one of the major constraints to small ruminant production in tropics (FAO, 1992; Diaz et al., 2000). Infection with gastrointestinal nematodes is regarded as one of the important factor causing production losses of livestock. Tangail district situated in central region of Bangladesh is very prospective for sheep rearing due to its geo- climatic condition. But the sheep rearing is hindered by various problems of which parasitic diseases might be one of the major problems because the mild winter and the long summer including the rainy season create a favorable environmental condition for the survival of various parasites with their intermediate host such as snail (Islam, 1969 and Haq and Sheikh, 1968). There is no precise report available on parasitic diseases of sheep in Bangladesh. Therefore, the present study was conducted to find out the prevalence of helminths of sheep at Tangail district and to determine the effect of age, sex, nutritional condition, management system and flock size of sheep, which would provide a basis for the understanding of different helminth parasites of sheep in formulating the control measures of the parasitic diseases.

\section{Materials and Methods}

The study was conducted for a period of six months from July to December 2010 at Tangail district of Bangladesh. Fecal samples of sheep were collected from the different areas of Tangail district and carried to the Laboratory for morphological examination of the parasites with their developmental stages. One hundred and ninety sheep were selected randomly irrespective of age, sex, nutritional status, management system and flock size. The age of the sheep were 5 months and above. Age of the sheep was determined by examining teeth as described by Rahman and Hossain (1997). According to age, sheep were divided into three groups, namely, lamb ( $\leq 1$ year), young (>1-2 years) and adult ( $>2$ years). The nutritional condition of sheep was categorized into two groups, namely, poor health and healthy according to eye inspection and body condition (Rahman and Hossain, 1997). The selected sheep were reared either in semi intensive or free range grazing system. The flock size was divided into three groups as small flock consisting of sheep 4-8, Medium flock had 9-12 sheep and the large flock were $>12$ sheep. After collection of all relevant information, sheep were restrained properly and all possible hygienic measures were maintained and feces were collected directly from the rectum. Some fresh fecal samples were collected from the ground immediately after voiding. A total of 190 samples were collected and 
about 5-10 gm of feces were collected from each sheep and kept in separate polythene bag, tied carefully, numbered properly and preserved in $10 \%$ formalin. The fecal samples were examined by Stoll's Ova counting technique and identification of egg of different helminths was performed by their characteristic morphological features as described by Soulsby (1982) and Rahman et al. (1996). Statistical analyses were carried out by using Statistical Package for Social Sciences (SPSS-11.5) technique using $\mathrm{F}$ test to detect the significant differences of mean values of eggs per gram of feces of identified helminths. Odds ratio of different parameters were calculated according to the formula given by Schlesselman (1982).

\section{Results and Discussion}

\section{Overall prevalence of helminths in sheep}

A total of 190 sheep were examined through fecal sample examination, of which 154 were infected with one or more species of helminths indicating $81.1 \%$ overall prevalence. Seven species of helminths were identified; of them three were trematodes, namely, Fasciola gigantica (8.4\%; Fig. 1), Paramphistomum spp. (44.2\%; Fig. 2), and Schistosoma indicum (3.7\%; Fig. 3); four were nematodes, namely, strongyles (62.6\%; Fig. 4), hookworm (19\%; Fig. 5), Trichuris spp. (2.1\%; Fig. 6), and Strongyloides spp. (9.5\%; Fig. 7). No cestodes were detected. It was observed that prevalence of Strongyles $(62.6 \%)$ was the highest, whereas Trichuris spp. (2.1\%) was the lowest (Table 1). Egg per Gram of Feces (EPG) was determined. EPG count was the highest in case of strongyles infection (100-1500) followed by Paramphistomum spp. (100-1100), hookworm (100-400), Fasciola gigantica (100-300), Strongyloides spp.(100-200), Schistosoma indicum (100-100) and Trichuris spp.(100-100). Mean EPG count was also higher in case of strongyles infection (430.3 \pm 99.9$)$ followed by Paramphistomum spp. (339.3 \pm 73.6$)$, hookworm (233.3 \pm 23.9$)$, Fasciola gigantica (162.5 \pm 20.2$)$ and Strongyloides spp. (116.7 \pm 9.6$)$. A low parasitic burden was in case of Schistosoma indicum and Trichuris spp. (100 \pm 0.0$)$.

Table 1. Overall prevalence of helminths in sheep in Tangail District

\begin{tabular}{|c|c|c|c|c|}
\hline \multirow{2}{*}{ Name of parasites } & \multirow{2}{*}{$\begin{array}{c}\text { No. of positive } \\
\text { cases } \\
(\mathrm{N}=190)\end{array}$} & \multirow{2}{*}{$\begin{array}{c}\text { Prevalence } \\
(\%)\end{array}$} & \multicolumn{2}{|c|}{ Egg per gram of feces (EPG) } \\
\hline & & & Range & Mean \pm SE \\
\hline Fasciola gigantica & 16 & 8.4 & $100-300$ & $162.5 \pm 20.2^{d}$ \\
\hline Paramphistomum spp. & 84 & 44.2 & $100-1100$ & $339.3 \pm 73.6^{b}$ \\
\hline Schistosoma indicum & 7 & 3.7 & $100-100$ & $100 \pm 0.0^{f}$ \\
\hline Hookworm & 36 & 19.0 & $100-400$ & $233.3 \pm 23.9^{C}$ \\
\hline Trichuris spp. & 4 & 2.1 & $100-100$ & $100 \pm 0.0^{\dagger}$ \\
\hline Strongyles & 119 & 62.6 & $100-1500$ & $430.3 \pm 99.9^{a}$ \\
\hline Strongyloides spp. & 18 & 9.5 & $100-200$ & $116.7 \pm 9.6^{\mathrm{e}}$ \\
\hline Total & $154^{*}$ & 81.1 & $100-1500$ & $211.7 \pm 32.5$ \\
\hline $\mathrm{P}$ value & & & & \\
\hline
\end{tabular}

* = Total number of animals infected is less than the summation of individual infection because same animal was infected by more than one type of helminths

$\mathrm{N}=$ Number of sheep examined

$* *=P<0.01$, figures in the $5^{\text {th }}$ column having different superscript varies significantly $(p<0.01)$

\section{Age related prevalence of helminths in sheep}

Age of the host had an effect on the prevalence of helminths in sheep. Prevalence of helminths in sheep was significantly higher $(p<0.01)$ in young sheep $(87.0 \%)$ than in adult $(83.3 \%)$ and in lamb $(70.9 \%)$. Young sheep were 3.8 and 1.3 times more susceptible than lambs and adults, whereas adults were 2.9 times more susceptible to helminth infection than lambs. Young sheep were infected by 7 different species of parasites. The adults and lambs were infected by 6 and 4 species, respectfully. Prevalence of helminths in lambs was the highest in case strongyles $(52.7 \%)$ followed by that of Paramphistomum spp. $(31.0 \%)$, hookworm (20\%) and Fasciola gigantica (7.3\%). Prevalence of helminths in young sheep was 
the highest in case of strongyles $(72.5 \%)$ followed by that of Paramphistomum spp. (56.5\%), hookworm (17.4\%), S. indicum (7.3\%), Fasciola gigantica (5.8\%), Strongyloides spp. (4.4\%), Trichuris spp. (2.9\%). Prevalence of helminths in adults was the highest in case of strongyles $(60.6 \%)$ followed by that Paramphistomum spp. (42.4\%), Strongyloides spp. (22.7\%), hookworm (19.7\%), F. gigantica (12.1\%) and S. indicum (3.0\%; Table 2).

Table 2. Age related prevalence of helminths in sheep in Tangail District

\begin{tabular}{|c|c|c|c|c|c|c|}
\hline \multirow{2}{*}{ Age } & \multirow{2}{*}{ Name of parasites } & \multirow{2}{*}{$\begin{array}{c}\text { No. of positive } \\
\text { cases }\end{array}$} & \multirow{2}{*}{$\begin{array}{c}\text { Prevalence } \\
(\%)\end{array}$} & \multicolumn{2}{|c|}{ Egg per gram of feces (EPG) } & \multirow{2}{*}{ Odds ratio } \\
\hline & & & & Range & Mean \pm SE & \\
\hline \multirow{5}{*}{$\begin{array}{l}\text { Lamb } \\
\text { ( } \leq 1 \text { year) } \\
n=55\end{array}$} & Fasciola gigantica & 4 & 7.3 & $100-200$ & $200.0 \pm 0.0$ & \multirow{5}{*}{$\begin{array}{c}\text { Young } \\
\text { vs Lamb = } \\
3.8\end{array}$} \\
\hline & Paraphistomum spp. & 17 & 31.0 & $100-800$ & $270.6 \pm 62.3$ & \\
\hline & Hookworm & 11 & 20.0 & $100-200$ & $200.0 \pm 0.0$ & \\
\hline & Strongyles & 29 & 52.7 & $100-1000$ & $455.2 \pm 55.4$ & \\
\hline & Sub total & $39 *$ & 70.9 & $100-1000$ & $281.4 \pm 29.4^{a}$ & \\
\hline \multirow{8}{*}{$\begin{array}{l}\text { Young } \\
\text { (>1-2year) } \\
n=69\end{array}$} & Fasciola gigantica & 4 & 5.8 & $100-100$ & $100.0 \pm 0.0$ & \multirow{8}{*}{$\begin{array}{l}\text { Young vs } \\
\text { Adult }=1.3\end{array}$} \\
\hline & Paraphistomum spp. & 39 & 56.5 & $100-1100$ & $389.7 \pm 50.6$ & \\
\hline & Schistosoma indicum & 5 & 7.3 & $100-100$ & $100.0 \pm 0.0$ & \\
\hline & Hookworm & 12 & 17.4 & $100-300$ & $250.0 \pm 33.7$ & \\
\hline & Trichuris spp. & 2 & 2.9 & $100-100$ & $100.0 \pm 0.0$ & \\
\hline & Strongyles & 50 & 72.5 & $100-1500$ & $360.0 \pm 56.5$ & \\
\hline & Strongyloides spp. & 3 & 4.4 & $100-100$ & $100.0 \pm 0.0$ & \\
\hline & Sub total & $60^{*}$ & 87.0 & $100-1500$ & $200 \pm 20.1^{c}$ & \\
\hline \multirow{7}{*}{$\begin{array}{l}\text { Adult } \\
\text { (>2year) } \\
n=66\end{array}$} & Fasciola gigantica & 8 & 12.1 & $100-300$ & $175.0 \pm 36.6$ & \multirow{7}{*}{$\begin{array}{c}\text { Adult vs } \\
\text { Lamb }=2.9\end{array}$} \\
\hline & Paraphistomum spp. & 28 & 42.4 & $100-1000$ & $310.7 \pm 53.3$ & \\
\hline & Schistosoma indicum & 2 & 3.0 & $100-100$ & $100.0 \pm 0.0$ & \\
\hline & Hookworm & 13 & 19.7 & $100-400$ & $246.2 \pm 31.3$ & \\
\hline & Strongyles & 40 & 60.6 & $100-1200$ & $500.0 \pm 72.0$ & \\
\hline & Strongyloides spp. & 15 & 22.7 & $100-200$ & $120.0 \pm 10.7$ & \\
\hline & Sub total & $55^{*}$ & 83.3 & $100-1200$ & $242.0 \pm 34.0^{b}$ & \\
\hline \multicolumn{2}{|l|}{$P$ value } & \multicolumn{4}{|c|}{$0.0006^{* *}$} & \\
\hline
\end{tabular}

$\mathrm{n}=$ No. of sheep examined

${ }^{*}=$ Total number of animals infected is less than the summation of individual infection because same animal was infected by more than one type of helminthes

${ }^{* *}=\mathrm{P}<0.01$

Figures in the $6^{\text {th }}$ column having different superscript varies significantly $(p<0.01)$.

\section{Sex related prevalence of helminths in sheep}

The prevalence of helminth infection was higher in female $(83.3 \%)$ than in the male $(79.3 \%)$ sheep. Female sheep were 1.2 times more susceptible than male. In male, prevalence was the highest in case of strongyles $(55.7 \%)$ followed by that of Paramphistomum spp. (47.2\%), Strongyloides spp. (8.5\%), F. gigantica (6.6\%), S. indicum (6.6\%), hookworm (5.7\%) and Trichuris spp. (3.8\%). In female, prevalence was the highest in case of strongyles $(71.4 \%)$ followed by that Paramphistomum spp. $(40.5 \%)$, hookworm (35.7\%), F. gigantica (10.7\%) and Strongyloides spp. (10.7\%; Table 3).

\section{Nutritional status related prevalence of helminths in sheep}

The prevalence of helminth infection was significantly $(p<0.01)$ higher in poor health sheep $(84.4 \%)$ than that in healthy sheep $(76.5 \%)$. Poor health sheep were 1.7 times more susceptible than the healthy sheep. In poor health sheep, prevalence was the highest in case of strongyles (82.6\%) followed by that of Paramphistomum spp. (52.3\%), hookworm (27.5\%), F. gigantica (12.8\%), Strongyloides spp. (12.8\%), S. indicum (6.4\%) and Trichuris spp. (2.8\%). On the other hand, in healthy sheep, prevalence was the highest in case of strongyles (35.8\%) followed by that of Paramphistomum spp. (33.3\%), hookworm (7.4\%), Strongyloides spp. (4.9\%), F. gigantica (2.5\%) and Trichuris spp. (1.2\%; Table 4). 
Table 3. Sex related prevalence of helminths in sheep in Tangail District

\begin{tabular}{|c|c|c|c|c|c|c|}
\hline \multirow[t]{2}{*}{ Sex } & \multirow[t]{2}{*}{ Name of parasites } & \multirow{2}{*}{$\begin{array}{l}\text { No. of positive } \\
\text { cases }\end{array}$} & \multirow{2}{*}{$\begin{array}{c}\text { Prevalence } \\
(\%)\end{array}$} & \multicolumn{2}{|c|}{ Egg per gram of feces (EPG) } & \multirow{2}{*}{ Odds ratio } \\
\hline & & & & Range & Mean \pm SE & \\
\hline \multirow{8}{*}{ male $(n=106)$} & Fasciola gigantica & 7 & 6.6 & $100-100$ & $114.3 \pm 14.3$ & \multirow{14}{*}{$\begin{array}{c}\text { Female vs } \\
\quad \text { Male } \\
=1.2\end{array}$} \\
\hline & Paraphistomum spp. & 50 & 47.2 & $100-1100$ & $346.0 \pm 47.3$ & \\
\hline & Schistosoma indicum & 7 & 6.6 & $100-100$ & $100.0 \pm 0.0$ & \\
\hline & Hookworm & 6 & 5.7 & $100-400$ & $300.0 \pm 44.7$ & \\
\hline & Trichuris spp. & 4 & 3.8 & $100-100$ & $100.0 \pm 0.0$ & \\
\hline & Strongyles & 59 & 55.7 & $100-1500$ & $540.7 \pm 60.7$ & \\
\hline & Strongyloides spp & 9 & 8.5 & $100-200$ & $133.3 \pm 16.7$ & \\
\hline & Sub total & $84^{*}$ & 79.3 & $100-1500$ & $233.5 \pm 26.2^{b}$ & \\
\hline \multirow{6}{*}{ Female $(n=84)$} & Fasciola gigantica & 9 & 10.7 & $100-300$ & $200.0 \pm 28.8$ & \\
\hline & Paraphistomum spp. & 34 & 40.5 & $100-600$ & $329.4 \pm 39.1$ & \\
\hline & Hookworm & 30 & 35.7 & $100-400$ & $220.0 \pm 16.2$ & \\
\hline & \begin{tabular}{|l|} 
Strongyles \\
\end{tabular} & 60 & 71.4 & $100-1000$ & $321.7 \pm 36.9$ & \\
\hline & Strongyloides spp. & 9 & 10.7 & $100-100$ & $100.0 \pm 0.0$ & \\
\hline & Sub total & $70^{*}$ & 83.3 & $100-1000$ & $234.2 \pm 24.2^{\mathrm{a}}$ & \\
\hline \multicolumn{2}{|l|}{$P$ value } & \multicolumn{4}{|c|}{$0.062^{N S}$} & \\
\hline
\end{tabular}

$\mathrm{N}=$ No. of sheep examined

${ }^{*}=$ Total number of animals infected is less than the summation of individual infection because same animal was infected by more than one type of helminths

NS $=$ Not significant

Table 4. Nutritional status related prevalence of helminths in sheep in Tangail District

\begin{tabular}{|c|c|c|c|c|c|c|}
\hline \multirow{2}{*}{$\begin{array}{l}\text { Nutritional } \\
\text { status }\end{array}$} & \multirow[t]{2}{*}{ Name of parasites } & \multirow{2}{*}{$\begin{array}{l}\text { No. of positive } \\
\text { cases }\end{array}$} & \multirow{2}{*}{$\begin{array}{c}\text { Prevalence } \\
(\%)\end{array}$} & \multicolumn{2}{|c|}{ Egg per gram of faeces (EPG) } & \multirow[t]{2}{*}{ Odds ratio } \\
\hline & & & & Range & Mean \pm SE & \\
\hline \multirow{8}{*}{$\begin{array}{c}\text { Poor } \\
\text { health } \\
(n=109)\end{array}$} & Fasciola gigantica & 14 & 12.8 & $100-300$ & $110.0 \pm 10.0$ & \multirow{15}{*}{$\begin{array}{c}\text { Poor health vs } \\
\text { Healthy }=1.7\end{array}$} \\
\hline & Paraphistomum spp. & 57 & 52.3 & $100-1100$ & $415.8 \pm 59.5$ & \\
\hline & Schistosoma indicum & 7 & 6.4 & $100-100$ & $100.0 \pm 0.0$ & \\
\hline & Hookworm & 30 & 27.5 & $100-400$ & $228.6 \pm 28.6$ & \\
\hline & Trichuris sp. & 3 & 2.8 & $100-100$ & $100.0 \pm 0.0$ & \\
\hline & Strongyles & 90 & 82.6 & $100-1500$ & $560.0 \pm 82.1$ & \\
\hline & Strongyloides spp & 14 & 12.8 & $100-200$ & $100.0 \pm 0.0$ & \\
\hline & Sub total & 92* & 84.4 & $100-1500$ & $230.6 \pm 30.0^{\mathrm{a}}$ & \\
\hline \multirow{7}{*}{$\begin{array}{l}\text { Healthy } \\
(n=81)\end{array}$} & Fasciola gigantica & 2 & 2.5 & $100-100$ & $250.0 \pm 22.4$ & \\
\hline & Paraphistomum spp. & 27 & 33.3 & $100-500$ & $276.1 \pm 29.7$ & \\
\hline & Hookworm & 6 & 7.4 & $100-200$ & $100.0 \pm 0.0$ & \\
\hline & Trichuris spp. & 1 & 1.2 & $100-100$ & $234.5 \pm 18.8$ & \\
\hline & Strongyles & 29 & 35.8 & $100-600$ & $100.0 \pm 0.0$ & \\
\hline & Strongyloides spp. & 4 & 4.9 & $100-100$ & $376.2 \pm 37.9$ & \\
\hline & Sub total & $62 *$ & 76.5 & $100-600$ & $125.0 \pm 13.1^{b}$ & \\
\hline \multicolumn{2}{|r|}{$P$ value } & \multicolumn{4}{|r|}{$0.0037^{* *}$} & \\
\hline
\end{tabular}

$\mathrm{n}=$ No. of sheep examined

${ }^{*}=$ Total number of animals infected is less than the summation of individual infection because same animal was infected by more than one type of helminths

$* *=P<0.01$ 


\section{Management system related prevalence of helminths in sheep}

Management system had a profound effect on the prevalence of helminth infection in sheep. The prevalence of helminth infection was higher in sheep reared in free range grazing system $(82.8 \%)$ than that in sheep reared in semi-intensive grazing system (79.1\%). Free range grazing sheep were 1.3 times more susceptible than semi-intensive grazing sheep. In free range grazing sheep, prevalence was the highest in case of Paramphistomum spp. (63.6\%) followed by that of strongyles $(31.3 \%)$, F. gigantica $(13.1 \%)$, hookworm (12.1\%), Strongyloides spp. (3.0\%) and S. indicum $(6.0 \%)$. On the other hand, in semi-intensive grazing sheep, prevalence was the highest in case of strongyles $(96.7 \%)$ followed by that of hookworm (26.4\%), Paramphistomum spp. (23.1\%), Strongyloides spp. (16.5\%), Trichuris spp. (4.3\%), F. gigantica (3.3\%) and S. indicum (1.1\%; Table 5).

Table 5. Management system related prevalence of helminths in sheep in Tangail District

\begin{tabular}{|c|c|c|c|c|c|c|}
\hline \multirow[t]{2}{*}{$\begin{array}{l}\text { Management } \\
\text { system }\end{array}$} & \multirow[t]{2}{*}{ Name of parasites } & \multirow{2}{*}{$\begin{array}{l}\text { No. of positive } \\
\text { cases }\end{array}$} & \multirow{2}{*}{$\begin{array}{l}\text { Prevalence } \\
\text { (\%) }\end{array}$} & \multicolumn{2}{|c|}{$\begin{array}{l}\text { Egg per gram of feces } \\
\text { (EPG) }\end{array}$} & \multirow[t]{2}{*}{ Odds ratio } \\
\hline & & & & Range & Mean \pm SE & \\
\hline \multirow{7}{*}{$\begin{array}{c}\text { Free } \\
\text { Ranging } \\
(n=99)\end{array}$} & Fasciola gigantica & 13 & 13.1 & $100-300$ & $114.3 \pm 14.3$ & \multirow{15}{*}{$\begin{array}{c}\text { Free Ranging } \\
\text { Vs } \\
\text { Semi- } \\
\text { intensive }=1.3\end{array}$} \\
\hline & Paraphistomum spp. & 63 & 63.6 & $100-1100$ & $253.8 \pm 30.7$ & \\
\hline & Schistosoma indicum & 6 & 6.1 & $100-100$ & $100.0 \pm 0.0$ & \\
\hline & Hookworm & 12 & 12.1 & $100-200$ & $237.5 \pm 20.7$ & \\
\hline & Strongyles & 31 & 31.3 & $100-900$ & $500.0 \pm 48.1$ & \\
\hline & Strongyloides spp. & 3 & 3.0 & $100-100$ & $120.0 \pm 10.7$ & \\
\hline & Sub total & $82^{*}$ & 82.8 & $100-1100$ & $220.9 \pm 24.8^{a}$ & \\
\hline \multirow{8}{*}{$\begin{array}{c}\text { Semi- } \\
\text { intensive } \\
(n=91)\end{array}$} & Fasciola gigantica & 3 & 3.3 & $100-200$ & $200.0 \pm 28.8$ & \\
\hline & Paraphistomum spp. & 21 & 23.1 & $100-1000$ & $413.3 \pm 51.6$ & \\
\hline & Schistosoma indicum & 1 & 1.1 & $100-100$ & $100.0 \pm 0.0$ & \\
\hline & Hookworm & 24 & 26.4 & $100-400$ & $225.0 \pm 25.0$ & \\
\hline & Trichuris spp. & 4 & 4.3 & $100-100$ & $100.0 \pm 0.0$ & \\
\hline & Strongyles & 88 & 96.7 & $100-1500$ & $319.6 \pm 52.8$ & \\
\hline & Strongyloides spp. & 15 & 16.5 & $100-200$ & $100.0 \pm 0.0$ & \\
\hline & Sub total & $72 *$ & 79.1 & $100-1500$ & $208.3 \pm 22.6^{b}$ & \\
\hline & $P$ value & \multicolumn{4}{|r|}{$0.065^{\mathrm{NS}}$} & \\
\hline
\end{tabular}

$\mathrm{n}=$ No. of sheep examined

* = Total number of animals infected is less than the summation of individual infection because same animal was infected by more than one type of helminths

NS $=$ Not significant

\section{Flock size related prevalence of helminths in sheep}

The prevalence of helminth infection was varied significantly $(p<0.01)$ among different flock size of sheep. The highest infection of helminth was in sheep of large flock sheep $(89.1 \%)$ followed by the sheep in small (81.8) and medium flock (73.9\%). Sheep of large flock were 2.9 and 1.8 times more susceptible than medium and small flocked sheep, respectively whereas, small flocked sheep were 1.6 times more susceptible in helminth infection than medium flocked sheep. In small flocked sheep, prevalence of helminths was the highest in case of strongyles $(72.7 \%)$ followed by hookworm $(24.2 \%)$, Paramphistomum spp. (22.7\%), Strongyloides spp. (12.1\%), F. gigantica (7.6\%), S. indicum (3.0\%) and Trichuris spp. (3.0\%). Prevalence of helminths in medium flocked sheep was the highest in case of Paramphistomum spp. (52.2\%) followed by strongyles (46.4\%), hookworm (14.5\%), Strongyloides spp. (7.3\%), F. gigantica (5.8\%) Trichuris spp. (4.4) and S. indicum (1.5\%). On the other hand, in large flocked sheep, prevalence was the highest in case of strongyles $(70.9 \%)$ followed by Paramphistomum spp. $(60.0 \%)$, hookworm (18.2\%), F. gigantica (12.7\%), Strongyloides spp. (9.1\%), S. indicum (7.3\%) and Trichuris spp. (3.6\%; Table 6). 
Table 6. Flock Size related prevalence of helminths in sheep in Tangail District

\begin{tabular}{|c|c|c|c|c|c|c|}
\hline \multirow[t]{2}{*}{ Flock size } & \multirow[t]{2}{*}{ Name of parasites } & \multirow{2}{*}{$\begin{array}{l}\text { No. of positive } \\
\text { cases }\end{array}$} & \multirow{2}{*}{$\begin{array}{c}\text { Prevalence } \\
(\%)\end{array}$} & \multicolumn{2}{|c|}{$\begin{array}{c}\text { Egg per gram of feces } \\
\text { (EPG) }\end{array}$} & \multirow[t]{2}{*}{ Odds ratio } \\
\hline & & & & Range & Mean \pm SE & \\
\hline \multirow{8}{*}{$\begin{array}{l}\text { Small } \\
(4-8 \text { no. }) \\
n=66\end{array}$} & Fasciola gigantica & 5 & 7.6 & $100-200$ & $100.0 \pm 0.0$ & \multirow{8}{*}{$\begin{array}{c}\text { Small } \\
\text { vs } \text { Medium }=1.6\end{array}$} \\
\hline & Paramphistomum spp. & 15 & 22.7 & $100-900$ & $257.1 \pm 47.7$ & \\
\hline & Schistosoma indicum & 2 & 3.0 & $100-100$ & $100.0 \pm 0.0$ & \\
\hline & Hookworm & 16 & 24.2 & $100-300$ & $255.0 \pm 24.5$ & \\
\hline & Trichuris spp. & 2 & 3.0 & $100-100$ & $100.0 \pm 0.0$ & \\
\hline & Strongyles & 48 & 72.7 & $100-1300$ & $511.6 \pm 56.0$ & \\
\hline & Strongyloides spp. & 8 & 12.1 & $100-200$ & $150.0 \pm 22.4$ & \\
\hline & Sub total & 54 & 81.8 & $100-1300$ & $228.9 \pm 25.1^{a}$ & \\
\hline \multirow{8}{*}{$\begin{array}{l}\text { Medium } \\
(9-12 \text { no. }) \\
n=69\end{array}$} & Fasciola gigantica & 4 & 5.8 & $100-300$ & $100.0 \pm 0.0$ & \multirow{8}{*}{$\begin{array}{c}\text { Large } \\
\text { vs } \text { Medium }=2.9\end{array}$} \\
\hline & \begin{tabular}{|l|} 
Paramphistomum spp. \\
\end{tabular} & 36 & 52.2 & $100-1100$ & $243.2 \pm 30.6$ & \\
\hline & Schistosoma indicum & 1 & 1.5 & $100-100$ & 100. $0 \pm 0.0$ & \\
\hline & Hookworm & 10 & 14.5 & $100-400$ & $207.7 \pm 21.1$ & \\
\hline & Trichuris spp. & 32 & 4.4 & $100-1000$ & $100.0 \pm 0.0$ & \\
\hline & Strongyles & 32 & 46.4 & $100-1000$ & $352.4 \pm 64.2$ & \\
\hline & Strongyloides spp. & 5 & 7.3 & $100-100$ & $100.0 \pm 0.0$ & \\
\hline & Sub total & 51 & 73.9 & $100-1100$ & $171.9 \pm 19.3^{c}$ & \\
\hline \multirow{8}{*}{$\begin{array}{l}\text { Large } \\
(>12 \text { no.) } \\
n=55\end{array}$} & Fasciola gigantica & 7 & 12.7 & $100-200$ & $176.9 \pm 23.1$ & \multirow{8}{*}{$\begin{array}{c}\text { Large } \\
\text { vs } \\
\text { small }=1.8\end{array}$} \\
\hline & Paramphistomum spp. & 33 & 60 & $100-1100$ & $481.8 \pm 64.7$ & \\
\hline & Schistosoma indicum & 4 & 7.3 & $100-100$ & $100.0 \pm 0.0$ & \\
\hline & \begin{tabular}{|l|} 
Hookworm \\
\end{tabular} & 10 & 18.2 & $100-200$ & $200.0 \pm 0.0$ & \\
\hline & Trichuris spp. & 2 & 3.6 & $100-100$ & $100.0 \pm 0.0$ & \\
\hline & Strongyles & 39 & 70.9 & $100-1500$ & $423.5 \pm 70.3$ & \\
\hline & Strongyloides spp. & 5 & 9.1 & $100-200$ & $100.0 \pm 0.0$ & \\
\hline & Sub total & 49 & 89.1 & $100-1500$ & $226.0 \pm 26.4^{b}$ & \\
\hline & $P$ value & & & & $0.0001^{* *}$ & \\
\hline
\end{tabular}

$\mathrm{n}=$ No. of sheep examined

${ }^{*}=$ Total number of animals infected is less than the summation of individual infection because same animal was infected by more than one type of helminths.

$* *=P<0.01$

Figures in the $6^{\text {th }}$ column having different superscript varies significantly $(p<0.01)$.

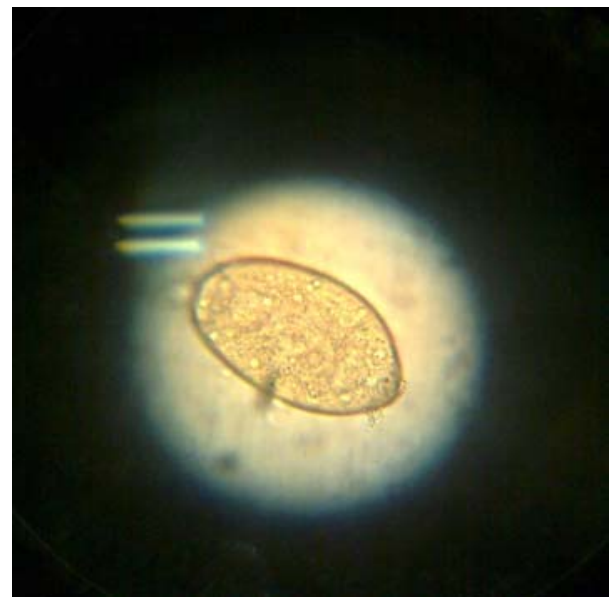

Fig. 1. Egg of Fasciola gigantica

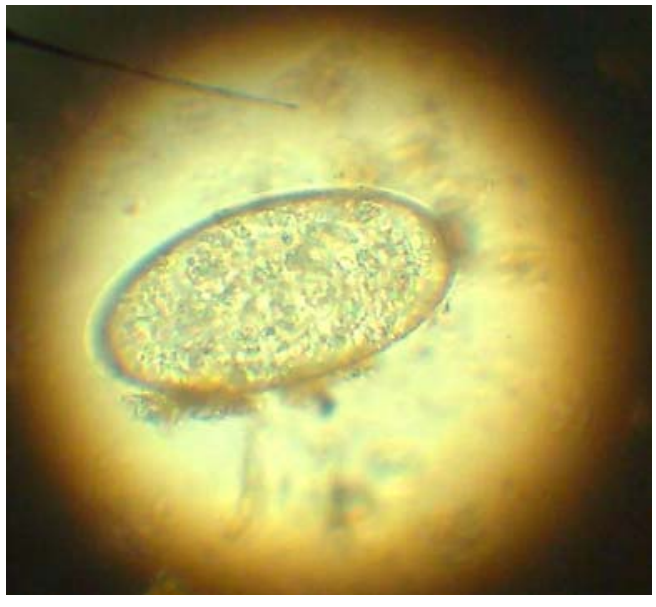

Fig. 2. Egg of Paramphistomum spp. 


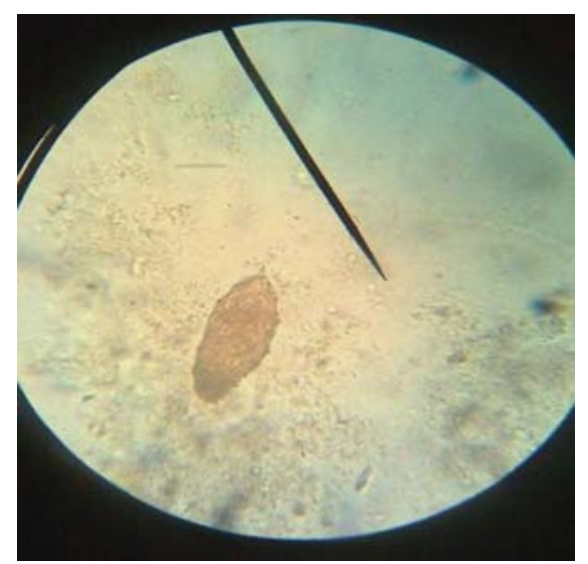

Fig. 3. Egg of Schistosoma indicum

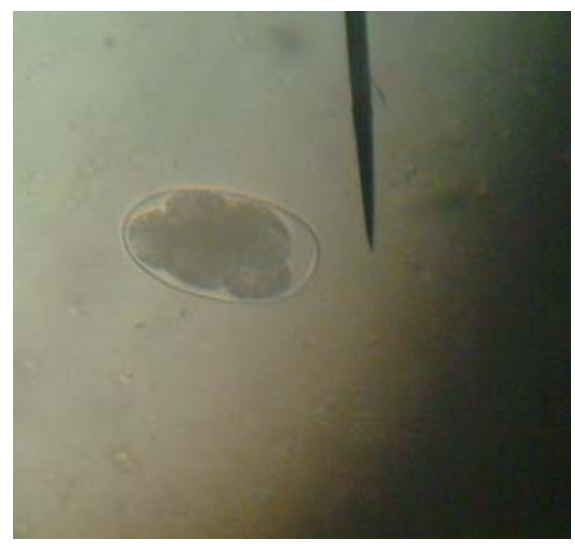

Fig. 5. Egg of Hookworm



Fig. 4. Egg of Strongyles



Fig. 6. Egg of Trichuris spp.

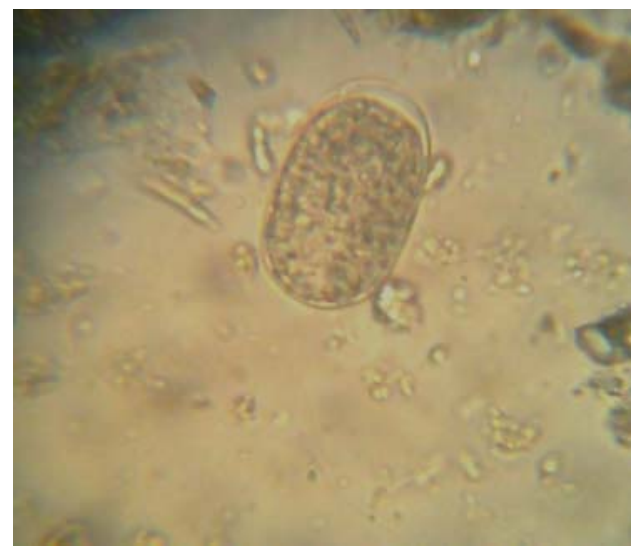

Fig. 7. Egg of Strongyloides spp.

Parasitism is of supreme importance in many agro-ecological zones and still a serious threat to the livestock economy worldwide (Vercruysse and Claerebout, 2001). Sheep are known to suffer from various endoparasites of which helminth infections are of great importance and remain one of the major constraints to small ruminant production in tropics (FAO, 1992; Diaz et al., 2000). 
The present study indicates that about $81.1 \%$ sheep were found infected with one or more helminths, namely, Fasciola gigantica (8.4\%), Paramphistomum spp. (44.2\%) Schistosoma indicum (3.7\%), hookworm (19.0\%), Trichuris spp. (2.1\%), strongyles (62.6\%) and Strongyloides spp. (9.5\%). Similar results were reported by Azad et al. (1997), Mbap and Chiroma (1998) and Oncel (2000). On the other hand, Mazid et al. (2006) in Mymensingh district, Bangladesh and Bezubik et al. (1969) in Poland reported $94.7 \%$ and $95.0 \%$ helminths infection in sheep, respectively. The present finding is higher than the earlier findings of ljaz et al. (2009), Gadahi et al. (2009), Asif et al. (2007) in Pakistan, Siddiqua (2010) in India, Khan et al. (2010) in Pakistan and Krishnappa et al. (1992) in India who reported 70.7\%, 63.5\%, $62 \%, 53.3 \%, 44.2 \%$ and $37.2 \%$ prevalence of helminths in sheep, respectively. The present findings is in agreement with the earlier findings of Siddiqua (2010) in India, Bhuyan (1970) in Bangladesh, Mir et al.(2008) in India and Mazyad and $\mathrm{Hi}$ (2002) in Egypt who recorded 5.4\%, 8.3\%, $10.0 \%$ and $11.8 \%$ fascioliasis in sheep, respectively. However, these results differ from the findings of Paz-silva et al. (2003) in Spain, Ratnaparkhi et al. (1993) and Bhatia et al. (1989) in India who reported higher (83.3\%, 81.4\% and $25.8 \%$, respectively) rate of Fasciola infection in sheep. The findings of the present study also differ from previous findings of Celep et al. (1995) in Turkey, Azad et al. (1997) in Pakistan, Okafor et al. (1988) in Nigeria and Oncel (2000) in Turkey showed, $40.8 \%, 16.3 \%, 13.7 \%$, and $4.0 \%$ prevalence of Paramphistomum spp., respectively. Chaudhri et al. (1994) in India and Islam (1969) in East Pakistan reported $33.2 \%$ and $10.0 \%$ sheep infected with Schistosoma indicum. The result of Trichuris spp. infection is similar to that of Mostafa et al. (1996) in Bangladesh (4.0\%) and Hashem and Sayed (1997) in Egypt (4.8\%) but different from Abebe and Esayas (2001) in Ethiopia (51.7\%), Achi et al. (2003) in Cote d' Ivoire (29\%) and Oncel (2000) in Turkey (28.0\%). This result of Strogyloides spp. infection differ from Abebe and Esayas (2001) in Ethiopia (38.0\%), Azad et al. (1997) in Pakistan (37.3\%) and Achi et al. (2003) in Cote d' Ivoire (31.0\%). The variation among the present and previous findings might be due to the differences in geographical locations, climatic conditions of the study area, rearing and management of sheep, nutritional condition of animals, sample size, and technique of sample examination.

It was revealed that age of the sheep had significant $(p<0.01)$ effect on helminth infections. Young sheep $(87.0 \%)$ were the most susceptible to infection followed by adults $(83.3 \%)$ and lambs $(63.6 \%)$, which supported the findings of Asif et al. (2007) who reported the higher prevalence of helminths infection in young animals compared to adult sheep in Pakistan $(p<0.059)$. But this result differed from that of Mazid et al. (2006) who reported higher prevalence of helminth parasites in younger $(<1$ year) and old $(\geq 2$ year) than in young ( $\geq 1<2$ year) sheep in Mymensingh, Bangladesh. The higher rate of infection with Fasciola gigantica was in older sheep, which is similar to the earlier reports of Bhuyan (1970) in Bangladesh and Aydenizoz and Yildiz (2002) in Turkey. But the present finding is in contrast to the previous reports of Al-Bayati et al. (1991) who observed higher prevalence of fascioliasis in young $(21.3 \%)$ than adults $(12.0 \%)$ and lamb $(7.3 \%)$ in Iraq. The findings of the present study is also similar to Lateef et al. (2005) in Pakistan with Strongylides infection, who observed higher prevalence in young animals but differ from Oka et al. (1999) in Cote d' Ivoire who stated that the highest infection was in animal below 1 year of age. This result is also dissimilar to Mazid et al. (2006) who reported older sheep were more susceptible to Paramphistomum infection than young (30.4\%) in Bangladesh. The exact cause of this variation in the prevalence of helminth infection in different age groups of sheep is due to immunological status of animals. But it may be assumed that the differences in the methodology, management factors may be the reasons of this variation.

It was observed that the prevalence of helminth infections was higher in females $(83.3 \%)$ than in male $(79.3 \%)$ sheep. This finding is in agreement with the earlier study of Mazid et al. (2006) in Bangladesh who recorded higher prevalence of helminth infection in females than in male sheep (78.6\%). But this report is in contrast to the previous report of Asif et al. (2007) who observed the sex-wise prevalence of helminths was higher in males than in females in Punjab, Pakistan. This result also differs from Okafor (1988) in Nigeria who observed that prevalence was not related to sex. The reason for higher prevalence of helminth infection in the females cannot be explained exactly but it might be assumed that the alteration in the physiological condition of the females during pregnancy, lactation and parturition as well as stresses leading to immunesuppression may be associated with this phenomenon. Higher level of prolaction and progesterone hormones makes the female individual more susceptible to any infection (Lloyd, 1983). 
The present study revealed that nutritional condition of sheep had significant $(p<0.01)$ effect with helminth infection. The higher prevalence of helminth infection was recorded in poor health $(75.2 \%)$ sheep than that in healthy (64.2\%) sheep. The present findings are in agreement with the earlier study of Lapage (1962) who found that malnourished animals are more susceptible to any infection as they are immunocompromised. The present study also agrees with the findings of Etter et al. (1999) who repoted that in immunocompromised animal the fecundity of parasites is usually increased.

The prevalence of helminth infection was higher in sheep reared in free ranged grazing system (82.8\%) than that in sheep reared in semi-intensive system (79.1) sheep. It was observed that fluke infection was higher in free ranged grazing sheep whereas nematode infection was higher in semi-intensively reared sheep. The present findings can not be compared due to lack of available relevant literatures. It is assumed that regular and direct contact of animals to the contaminated pastures may be associated with this phenomenon.

It was revealed that the prevalence of helminths was significantly $(p<0.01)$ higher in large flocked sheep (89.1\%) than in small (81.8) and medium flocked (73.9\%) sheep. The influence of flock size on the prevalence of helminths is difficult to explain exactly but it is assumed that crowding of animals, lower feed supplement and management practices may be associated with this variation.

\section{Conclusion}

The prevalence of helminth parasites of sheep at Tangail district, Bangladesh was highly susceptible to helminth infections. Age, nutritional status and flock size of sheep significantly $(p<0.01)$ influenced the prevalence of helminth infections. Identification of the helminths down to species through ova detection is very difficult, and it may be better to isolate mature or immature helminths directly from the visceral organ of the sheep. Further study should be carried out to determine the economic losses due to helminthiasis of sheep and to develop effective control measures against it.

\section{References}

Abebe, W. and Esayas, C. 2001. Survey of ovine and caprine gastrointestinal helminthosis in eastern part of Ethiopia during the dry season of the year. Revue de Medecine Veterinarie, 152: 379-384.

Achi, Y.L., Zinsstag, J., Yeo, N., Dea, V. and Dorchies, P. 2003. Epidemiology of parasites of sheep and goats from savannah area in Cote d'Ivoire. Revue de Medecine Veterinaire, 154(3): 179-188.

Al-Bayati, M.M., Al-Khalidi, N.W., and Altaif, K.I. 1991. Fascioliasis in sheep in Mosul, Iraq: the infection rate and the seasonal variation. Journal of Veterinary Parasitology, 5(1): 45-47.

Asif, R.M., lqbal, Z., Jabbar, A. and Yaseen, M. 2007. Point prevalence of gastrointestinal helminthiasis in ruminants in southern Punjab, Pakistan. Journal of Helminthology, 81(3): 323-328.

Aydenizoz, Z. and Yildiz, K. 2002. Prevalence of liver trematodes in sheep slaughtered in Kirikkale. Turkiye Parazitoloji Dergisi, 26(3): 317-319.

Azad, E., Khan, S.A., Khan, R.M, and Khan, M.M. 1997. Prevalence of gastrointestinal helminth parasites of sheep and goats in Quetta district of the Province of Baluchistan, Pakistan. Pakistan Journal of Zoology, 29(3): 259-262.

Bezubik, B.B., Uadhaya, D.S., and Juyal, P.D. 1969. The helminth parasites of Carpathian sheep in poland. Acta parasitology, Poland, 17(1/19): 25-37.

Bhatia, B.B., Uadhaya, D.S., and Juyal, P.D. 1989. Epidemiology of Fasciola gigantica in buffaloes, goats and sheep in Tarai region of Uttar Pradesh, India. Journal of Veterinary Parasitology, 3(1): 25-29.

Bhuyan, M.A. 1970. A survey of helminths parasiting the liver of domesticated ruminants in East Pakistan. MS Thesis, Department of Parasitology, Bangladesh Agricultural University, Mymensingh.

Celep, A., Acici, M., Cetindag, M., and Gurbuz, I. 1995. Parasito-epidemiological studies in sheep in the Samsun region, Turkey. Turkiye Parasitology Dergisi, 19(2): 290-296.

Chaudhri, S.S., Kumar, S., and Gupta, R.P. 1994. Prevalence of Schistosoma indicum in Haryana and treatment trials in sheep. Indian Veterinary Journal, 71(3): 291-292.

Diaz, R.P., Torres, H.G., Osorio, A. M. M., Perez, H.P., Pulido, A.A.R., Becerril, P.A.M., and Herrera, H.J.G. 2000. Resistencia genetica a parasitos gastrointestinales en ovinos Florida, Pelibuay y sus cruzas en el tropico Mexicano, Agrociencia, 34: 13-20.

Etter, E., Chartier, C., Hoste, H. and Borgida, L.P. 1999. The influence of nutrition on the peri parturient rise in faecal egg counts in dairy goat; Results from a two years study.Revue de medicine Veterinaire, 150(12): 975-980. 
FAO, 1992. Distribution and impact of helminth diseases of livestock in developing countries. FAO Animal Production and Health Paper, Vol. 96. FAO, Rome, p. 221.

Gadahi, J.A., Arshed, M.J., Ali, Q., Javaid, S.B. and Shah, S.I. 2009. Prevalence of gastrointestinal parasites of sheep and goat in and around Rawalpindi and Islamabad, Pakistan. Veterinary World, 2(2): 51-53.

Haq, S. and Shaikh, H. 1968. A Survey of helminth parasiting the gastrointestinal tracts of goats and sheep in East Pakistan. East Pakistan Journal Veterinary Science, 2 (2): 54-62.

Hashem, M.S.and Sayed,M.H. 1997. Helminth parasites of sheep in Dakahlia province- Egypt. Assiut Veterinary Medical Journal, 38(75): 48-54

Ijaz, M., Khan, M.S., Avais, M., Ashraf, K., Ali, M.M., and Khan, M.Z.U. 2009. Infection rate and chemotherapy of various helminthes in diarrhoeic sheep in and around Lahore. The Journal of Animal \& Plant Sciences, 19(1): 13-16.

Islam, K.S. 1969. Incidence of schistosomiasis in domesticated ruminants in East Pakistan. M.S. Thesis, the Department of Parasitology, Bangladesh Agricultural University, Mymensingh.

Khan, M.N., Sajid, M.S., Khan, M.K., Iqbal, Z. and Hussain, A. 2010. Gastrointestinal helminthiasis: prevalence and associated determinants in domestic ruminants of district Toba Tek Singh, Punjab, Pakistan. Parasitology Research, 107(4):787-794.

Krishnappa, K., Parimal, R., Balasubramaniah, G.A., Ramaswamy, V. and Roy, P. 1992. Studies on helminthiasis of sheep in Dharmapuri area of Tamil Nadu, India. Indian Veterinary Medical Journal, 16(4): 317-318.

Lapage, G. 1962. Monig's Veterinary Helminthology and Entomology, $5^{\text {th }}$ edition. Bailiere, Tindall and Cox Ltd. London, UK. pp: 556-723.

Lateef, M., Iqbal, Z., Jabbar, A., Khan, M.N. and Akhter, M.S. 2005. Epidemiology of trichostrongylid nematode infections in sheep under Traditional Husbandry System in Pakistan. International Journal of Agriculture and Biology, 7(4): 596-600.

Lloyd, S. 1983. Effect of pregnancy and lactation up on infection. Veterinary immunology Immunopathology, 4: 153-176.

Mazid, M.A., Bhattacharjee, J., Begum, N. and Rahman, M.H. 2006. Helminth parasites of the digestive system of sheep in Mymensingh, Bangladesh. Bangladesh Journal of Veterinary Medicine, 4(2): 117-122.

Mazyad, S.A., and HI el-Nemr. 2002. The endoparasites of sheep and goats, and shepherd in North Sinai Governorate, Egypt. Journal of the Egyptian Society of Parasitology, 32(1): 119-126.

Mbap, S.T., and Chiroma, B.Y. 1998. The effects of breed and environmental factors on helminth infection of sheep in bauchi, Nigeria. School of Agriculture, ATBU, PMB 0248, Bauchi, Nigeria. Proceedings of the $6^{\text {th }}$ World Congress on Genetics Applied to Livestock Production, Armidale, NSW, Australia, 11-16 January, Volume 25: 261-264.

Mir, R.A., Chishti, M.Z., Zarger, M.A., Tak, H. and Dar, F.A. 2008. Seasonal prevalence of trematode parasites of sheep (Ovis aries L.) in Kashmir Valley, India. Nigerian Journal of Parasitology, 29 (2): 80-83.

Mostofa, M., Mckellar, Q.A. and Alam, M.N. 1996. Epidemiology of gastrointestinal helminth parasites in small ruminants in Bangladesh and their anthelmintic therapy. SPCSR, ACAIR Publication, Australia, 74: 105-108.

Oka, C.K., Zinsstag, J., Pandey, V.S., Fofana, F. and Depo, N.A. 1999. Epidemiology of parasites of sheepin the southern forest zone of Cote d'Ivoire. LANADA, Laboratoire central de pathologie animal de Bingerville, BP 206, Bingerville, Cote d'Ivoire. Revue d'Elevage et de Medecine Veterinaire des pays Tropicaux, 52 (1): 39-46.

Okafor, F.C., Mbata, G., and Anosike, J. 1988. Studies on Paramphistomum cervi (Schrank, 1790) infections of ruminants in Imo state, Nigeria with special reference to the role played by Builness b.forskalii (Ehrenberg) in there transmission. Bulletin of Animal Health and production in Africa, 38(2): 142-146.

Oncel, T. 2000. The prevalence of helminth species in sheep in the southern region of Marmara, Turkey. Turkiye Parazitoloji Dergisi, 26(3): 317-319.

Paz-Silva, A., Sanchez-Andrade, R., Suarez, J.L., Pedreira, J., Arias, M., Lopez, C., panadero, R., Diaz, P., Diez-Banos, P. and Morrondo, P. 2003. Prevalence of natural ovine fascioliasis shown by demonstrating the presence of serum circulating antigens. Parasitology Research, 91(4): 328-331.

Rahman, M.A. and Hossain, W.I.M.A. 1997. Introductory Animal Hygiene and Management, $1^{\text {st }}$ edition, Department of Microbiology and Hygiene, Bangladesh Agricultural University, Mymensingh. pp. 7-34.

Rahman, M.H., Ahmed, S. and Mondal, M.M.H. 1996. Helminths parasites of cattle (Bos indicus) in Bangladesh. Indian Journal of Parasitology. 7(2): 173-174.

Ratnaparkhi, M.R., Shastri, U.V., Narladkar, B.W., Degloorkar, N.M. and Digraskar, S.U. 1993. A short note on prevalence of Fasciola infection in domestic animals in Parbhani District, India. Indian Journal of Animal Health, 3(1): 83-85.

Schlesselman, J.J. 1982. Case Control Studies, $1^{\text {st }}$ edition, Oxford University Press, New York, pp: 174-177.

Siddiqua and Banu 2010. Incidence of common helminth parasites in goats and sheep in Ghatampur Area of Kanpur Dehat. Trends in Biosciences, 3(1): 60-68.

Soulsby, E.J.L. 1982. Helminths, Arthropod and Protozoa of Domesticated Animals. $7^{\text {th }}$ edition, Bailliere Tindal and Cassell Ltd., London, pp. 757-759.

Vercruysse, J. and Claerebout, E. 2001. Treatment vs. non-treatment of helminth infections in cattle: defining the thresholds. Veterinary Parasitology, 98: 195-214. 